\title{
Fabrication and functionalization of PCB gold electrodes suitable for DNA-based electrochemical sensing
}

\author{
P. Salvo ${ }^{\text {a,b,* }}$, O.Y.F. Henry ${ }^{c}$, K. Dhaenens ${ }^{\text {a,b }}$, J.L. Acero Sanchez ${ }^{c}$, A. Gielen ${ }^{\text {a,b }}$, \\ B. Werne Solnestam ${ }^{\mathrm{e}}$, J. Lundeberg ${ }^{\mathrm{e}}$, C.K. O’Sullivan ${ }^{\mathrm{c}, \mathrm{d}}$ and J. Vanfleteren ${ }^{\mathrm{a}, \mathrm{b}}$ \\ ${ }^{\text {a }}$ Faculty of Engineering, Centre for Microsystems Technology, University of Ghent, Ghent-Zwijnaarde, \\ Belgium \\ ${ }^{\mathrm{b}}$ Interuniversity Microelectronics Centre, Leuven, Belgium \\ ${ }^{\mathrm{c}}$ Department of Chemical Engineering, Universitat Rovira i Virgili, Tarragona, Spain \\ ${ }^{\mathrm{d}}$ Institució Catalana de Recerca i Estudis Avançats, Barcelona, Spain \\ ${ }^{\mathrm{e}}$ Science for Life Laboratory (SciLifeLab Stockholm), KTH Royal Institute of Technology, \\ School of Biotechnology, Division of Gene Technology, Solna, Sweden
}

Received 6 November 2012

Accepted 26 December 2013

\begin{abstract}
The request of high specificity and selectivity sensors suitable for mass production is a constant demand in medical research. For applications in point-of-care diagnostics and therapy, there is a high demand for low cost and rapid sensing platforms. This paper describes the fabrication and functionalization of gold electrodes arrays for the detection of deoxyribonucleic acid (DNA) in printed circuit board (PCB) technology. The process can be implemented to produce efficiently a large number of biosensors. We report an electrolytic plating procedure to fabricate low-density gold microarrays on PCB suitable for electrochemical DNA detection in research fields such as cancer diagnostics or pharmacogenetics, where biosensors are usually targeted to detect a small number of genes. PCB technology allows producing high precision, fast and low cost microelectrodes. The surface of the microarray is functionalized with self-assembled monolayers of mercaptoundodecanoic acid or thiolated DNA. The PCB microarray is tested by cyclic voltammetry in presence of $5 \mathrm{mM}$ of the redox probe $\mathrm{K}_{3} \mathrm{Fe}\left(\mathrm{CN}_{6}\right)$ in $0.1 \mathrm{M} \mathrm{KCl}$. The voltammograms prove the correct immobilization of both the alkanethiol systems. The sensor is tested for detecting relevant markers for breast cancer. Results for $5 \mathrm{nM}$ of the target TACSTD1 against the complementary TACSTD1 and non-complementary GRP, MYC, SCGB2A1, SCGB2A2, TOP2A probes show a remarkable detection limit of $0.05 \mathrm{nM}$ and a high specificity.
\end{abstract}

Keywords: Printed circuit board gold electrodes, electrolytic plating, surface functionalization, thiolated DNA probes, breast cancer markers detection

\footnotetext{
*Address for correspondence: P. Salvo, Faculty of Engineering, Centre for Microsystems Technology (CMST), University of Ghent, 914A Technologiepark, B-9052 Ghent-Zwijnaarde, Belgium. Tel.: +32 926453 54; Fax: +32 926453 74; E-mail: pietro.salvo@gmail.com.
} 


\section{Introduction}

Monitoring of biological events has greatly benefited from the technological advances in the fabrication of electrochemical sensors. An impressive number of biomedical devices have been proposed and the tendency is to move towards lab-on-a-chip (LOC) systems [1]. In point-of-care applications, e.g. cancer diagnostics and personalised therapy, LOCs can be combined with low-density microarrays for detecting specific sequence of genes. As point-of-care screening tool, low density microarrays can represent a low cost and rapid alternative in over existing expensive and time-consuming systems such as high-density DNA microarrays [2,3]. In a typical LOC, the molecule of interest is investigated by studying the effects produced by its interaction with a known molecule immobilized on a solid surface. In general, several factors influence the analytical result on a solid electrode, namely the surface properties (e.g. cleanliness, structure and chemistry), the type of electrode material, and electronic characteristics [4]. Therefore, a key aspect in improving the performance of LOC microfluidic devices is the choice of the materials, which have to enable the realization of biological assays (e.g. DNA assays) and be amenable to micro-fabrication or photolithography. Common materials, often used in combination or as bare substrates, are glass, silicon, silicon oxide, mica and gold but diamond thin film, indium tin oxide (ITO) and carbon paste are possible alternatives [5,6]. Gold is widely known for its biocompatibility and its use is frequent in biosensors [7,8]. The deposition of gold on a substrate, which is usually associated with an adhesion promotion layer such as Ti/W, palladium, chromium and nickel, is mainly accomplished by sputtering [9], chemical or physical evaporation on silicon, mica and glass wafers [10-13], and electroless plating [14-16]. Although the devices based on these materials and methods are well established, electrochemical deoxyribonucleic acid (DNA) biosensors can take advantage of the printed circuit board (PCB) technology, which is cost effective and allows large-scale production and a high grade of miniaturization [17,18]. Other relevant advantages of PCB technology is that the probability of error is negligible and the repeatability of experiments is improved. A crucial parameter in the performance of electrochemical DNA assays is the quality of the metal electrode used. The simplest approach to the formation of efficient DNA sensing surfaces consists in the self-assembly of thiolated DNA strands onto gold [19]. Gold is typically preferred due to its inertness and stability for DNA immobilization as well as wide electroanalytical potential working range. The self-assembly process has been extensively reported and will readily result in packed monolayers. Nonetheless, the quality of the monolayer, and consequently that of the sensor, will closely depend on the quality of the underlying metal layer. Furthermore, the contamination of the gold surface with other metals such as copper, nickel or cobalt will result in a loss of electrochemical stability and unstable monolayers. As such the ideal gold layer should be uniform, defect free (i.e. non-porous or pinholes free) and of the highest purity.

In the present study, an electrolytic fabrication and a functionalization process for low-density microarrays on FR4 PCBs for point-of-care applications are presented. These techniques are suitable for the development of biosensors for theranostics and can be implemented in small labs or extended to mass production. The fabrication process consists of PCB micro-etching and surface preparation and the deposition of a thick pure gold layer on standard FR4 copper PCBs, with nickel as adhesion promoter. The electrodes are functionalized with mercaptoundodecanoic acid or thiolated DNA and a proof of their suitability for electrochemical DNA sensing is reported when tested against six markers relevant for breast cancer. 


\section{Materials and methods}

\subsection{Electrode design}

All electrochemical DNA assay measurements are performed with a potentiostat/galvanostat PGSTAT 12 Autolab controlled with the General Purpose Electrochemical System (GPES) software and equipped with a MUX module (Eco Chemie B.V., The Netherlands). The MUX module allows sequential addressing of up to 64 working electrodes that share the same counter and reference electrode. As such, the electrode chip, which is a square with a side-length of $22.6 \mathrm{~mm}$, consists of 64 individually addressable $300 \mu \mathrm{m}$ diameter working electrodes, a common counter electrode and common reference electrode. Internal reference and counter electrodes are used for the DNA assays, whilst an external platinum counter electrode and $\mathrm{Ag} / \mathrm{AgCl}$ wire reference electrode are used for the electrochemical characterisation of the gold layers.

\subsection{Electrolytic gold plating}

The initial substrate is a 4-in square FR4 board with $18 \mu \mathrm{m}$ copper on it, which allows fabricating four DNA detectors per time. Before plating, every PCB is patterned to define the copper tracks by a standard photolithography process.

\subsubsection{Nickel plating}

Copper is cleaned at room temperature (RT) for $5 \mathrm{~min}$ in a $5 \%$ solution of Electroposit ${ }^{\mathrm{TM}} \mathrm{PC}$ Cleaner (Rohm and Haas Electronic Materials). After that, the PCB is rinsed with DI water in a beaker for 2 min at RT followed by spray rinsing with DI water. The nickel adhesion is promoted by the micro-etch Circuposit ${ }^{\mathrm{TM}}$ Etch 3336 (Rohm and Haas Electronic Materials). The etched copper is approximately $300 \mathrm{~nm}$ for $1 \mathrm{~min}$ of micro-etch at RT. To remove residual salts after micro-etching from the copper surface, the PCB is sequentially dipped in two beakers filled with DI water for $2 \mathrm{~min}$ at RT, respectively, and in a $10 \%$ sulphuric acid solution for $1 \mathrm{~min}$ at RT. The previous step completes the copper surface cleaning.

The nickel plating bath volume is 21 and consists of $810 \mathrm{ml}$ of nickel sulphamate solution (LECTRONIC ${ }^{\text {TM }} 10-03 \mathrm{~S}$ by Enthone ${ }^{\mathrm{TM}}$ ), $80 \mathrm{~g}$ of boric acid to avoid large variations in bath $\mathrm{pH}$ during the plating cycle, $130 \mathrm{ml}$ of LECTRO-NIC ${ }^{\text {TM }}$ 10-03 Anode activator to increase the conductivity, $24 \mathrm{ml}$ of LECTRO-NIC ${ }^{\text {TM }}$ 10-03 Addition agent to minimize the stress during plating, $20 \mathrm{ml}$ of LECTRO-NIC ${ }^{\text {TM }}$ $10-03$ Wetting agent to reduce the bath contamination and DI water, which is added until 21 is reached.

High purity sulphide nickel anodes are used for the plating after an accurate cleaning in $3 \% \mathrm{HCl}$ solution for $1 \mathrm{~h}$ at $50^{\circ} \mathrm{C}$. After rinsing with DI water, they are soaked for $15 \mathrm{~min}$ in 11 of boiling DI water with $5 \mathrm{ml}$ LECTRO-NIC ${ }^{\text {TM }} 10-03 \mathrm{~S}$. The bags are then soaked for $10 \mathrm{~min}$ at RT in 5\% sulphuric acid solution and eventually rinsed with DI water. Thereafter, the anodes are left in a $10 \% \mathrm{HNO}_{3}$ solution until their surface is visibly clean and eventually rinsed with DI water for $1 \mathrm{~min}$.

The plating is performed at $57^{\circ} \mathrm{C}$ by supplying $1.5 \mathrm{~A} / \mathrm{dm}^{2}$ cathodic current density. Subsequently, the PCB is rinsed at $35^{\circ} \mathrm{C}$ for 2 min in DI water. During our tests, it has been seen that this intensity is able to ensure a better uniformity of the final nickel layer compared to higher values. The cathode surface, i.e. the total copper area, is $37.94 \mathrm{~cm}^{2}$ and is calculated by PCB layout software (CleWin by WieWeb Software). Therefore, this surface requires $570 \mathrm{~mA}$ for $16 \mathrm{~min}$ and $16 \mathrm{~s}$ (NTN $140 \mathrm{M}-12.5$ power supply by FuG Elektronik) resulting in $5 \mu \mathrm{m}$ nickel thickness. 


\subsubsection{Strike-gold plating}

A mild acid cyanide strike-gold bath is used as a barrier to minimize the drag-in of contaminates into the successive gold plating bath, and furthermore, to promote the adhesion and reduce the porosity of the thicker gold layer on the top of the structure. This process starts by soaking the PCB in DI water for 2 min at RT. To remove residuals salts, as for copper etching, the PCB is cleaned in a $20 \% \mathrm{H}_{2} \mathrm{SO}_{4}$ solution at $35^{\circ} \mathrm{C}$ for $30 \mathrm{~s}$ and then rinsed twice in two different beakers in DI water for 2 min at RT. The strike-gold bath is prepared by means of AUROBOND ${ }^{\mathrm{TM}} \mathrm{TN}$ (Enthone ${ }^{\mathrm{TM}}$ ) and consists of 1.21 AUROBOND ${ }^{\mathrm{TM}} \mathrm{TN} \mathrm{B}, 5.85 \mathrm{~g}$ of $\mathrm{KAu}(\mathrm{CN}) 68.3 \%$, and DI water added to reach 21 solution. The strikegold plating is carried out with anodes of Pt/Ti-type at $50^{\circ} \mathrm{C}$ by supplying $1 \mathrm{~A} / \mathrm{dm}^{2}$ cathodic current density, which corresponds to a current equal to $380 \mathrm{~mA}$, for $1 \mathrm{~min} 20 \mathrm{~s}$. The thickness of the deposited gold is roughly $200 \mathrm{~nm}$. The strike-gold step is completed by rinsing the PCB in DI water at $35^{\circ} \mathrm{C}$ for $2 \mathrm{~min}$ and successively at RT for $2 \mathrm{~min}$.

\subsubsection{Gold plating}

The electrolytic process is completed by an alkaline non-cyanide bath to plate a $3 \mu \mathrm{m}$ thick gold layer. The bath is based on NEUTRONEX ${ }^{\mathrm{TM}} 309$ and is composed of 1.21 NEUTRONEX $^{\mathrm{TM}} 309 \mathrm{~B}$ (Enthone ${ }^{\mathrm{TM}}$ ) which only contains the additives for the bath, $200 \mathrm{ml}$ of BDT-X complex (Enthone ${ }^{\mathrm{TM}}$ ) which contains $20 \mathrm{~g}$ of gold, and DI water added to adjust the final volume to 21 . Gold plating is carried out at $50^{\circ} \mathrm{C}$. A cathodic current density of $0.4 \mathrm{~A} / \mathrm{dm}^{2}$, i.e. a current of $150 \mathrm{~mA}$, is supplied for $11 \mathrm{~min}$ $49 \mathrm{~s}$. The PCB is rinsed with DI water at $35^{\circ} \mathrm{C}$ for 2 min followed by 2 min at RT. The electrodes are ultimately dried by nitrogen gun.

The active electrodes area is defined by applying a solder mask layer on the PCB. Each DNA detector is cut out from the PCB by a metal guillotine. The final result is shown in Figs 1 and 2.

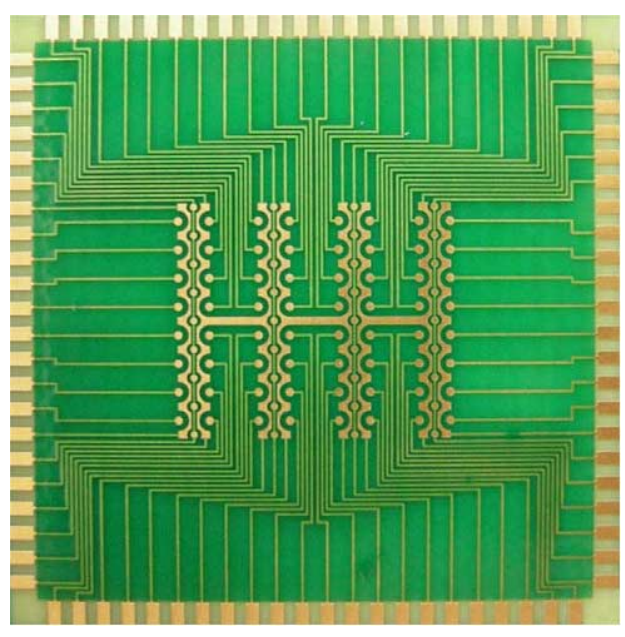

Fig. 1. Electrolytically gold plated DNA detector on PCB. Solder mask (green) is used to isolate non-active areas. (The colors are visible in the online version of the article; http:// dx.doi.org/10.3233/BME-140982.)

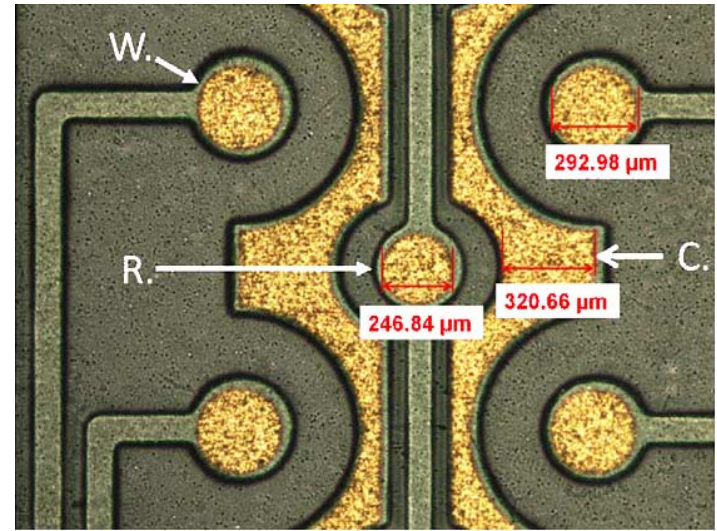

Fig. 2. Detail of the DNA detector (optical microscope). Solder mask (grey) is well defined. (W. - Working electrode; C. - Counter electrode; R. - Reference electrode.) (Colors are visible in the online version of the article; http://dx.doi.org/ 10.3233/BME-140982.) 


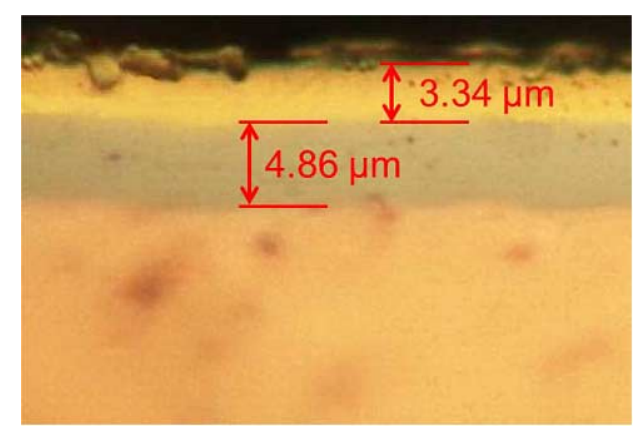

Fig. 3. Cross-section of the sample plated with $3 \mu \mathrm{m}$ gold. The bottom is the copper layer. The nickel layer is reasonably coincident with the $5 \mu \mathrm{m}$ described in the process protocol in both cross-sections. The top gold layer consists of strike-gold $(200 \mathrm{~nm})$ and the thick gold layer. An acceptable small deviation of $140 \mathrm{~nm}$ is observed. Impurities due to cross-sectioning are visible on the top of both samples. (Colors are visible in the online version of the article; http://dx.doi.org/10.3233/BME-140982.)

\subsection{Cross-section}

The accuracy of the electrolytic plating is initially evaluated by measuring the effective nickel and gold thicknesses in a cross-section analysis of the fabricated substrate. Figure 3 shows an optical image (Nikon Optiphot 200) of the cross-section. Both the nickel and gold, i.e. strike-gold and thick gold, layers present an acceptable small deviation of $140 \mathrm{~nm}$ from the thicknesses specified in the process protocol. It has to be noted that the distances are manually taken by the operator and, thus, a minimal amount of error is likely to be present. However, repeated measurements only show a difference of few nanometres. These small differences with the target thickness can be neglected and, hence, the resulting PCB is compatible with electrolytic plating defined in Section 2.

\section{Functionalization}

The DNA probes are designed in-silico and synthetic single stranded DNA (ssDNA) oligonucleotides of the selected sequences have been purchased as lyophilized powder from Eurofin MWG Operon GmbH (Germany) and reconstituted in Rnase and Dnase-free MilliQ water. The DNA probes have been supplied with an amino termination at the $5^{\prime}$-end and thiolated in house.

TACSTD1 probe: $5^{\prime}-\mathrm{SH}-\mathrm{T}_{15}$-CTC CTT CTCCTT CTT CTCCCT CC-3'

HRP-labelled Complementary: 5'-HRP-C 6 -TCC AAC CCT TAG GGA ACC C-3'

TACSTD1 target:

5'-GGG TTC CCT AAG GGT TGG ACC GCA GCT CAG GAA GAA TGT GTC TGT GAA AAC TAC AAG CTG GCC GTA AAC TGC TTT GTG GGA TCG GAG GGA GAA GAA GGA $\boldsymbol{G A \boldsymbol { A }} \boldsymbol{G G A}$ GTC TAG ATT GGA TCT TGC TGG CGC GTC C-3' GRP probe: $5^{\prime}-\mathrm{SH}_{-} \mathrm{T}_{15}$-CCC TCT CTT TCC CTT TCC TCC CT MYC probe: $5^{\prime}-\mathrm{SH}-\mathrm{T}_{15}-\mathrm{CCC}$ TCC TTC TTC TCC TCT TTC CC SCGB2A1 probe: $5^{\prime}-\mathrm{SH}-\mathrm{T}_{15}-\mathrm{CCC}$ TCC CTC TTT CCT CCC TCT TT SCGB2A2 probe: $5^{\prime}-\mathrm{SH}-\mathrm{T}_{15}-\mathrm{CCC}$ TCT TCC TCC TTT CTT TCC TT TOP2A probe: $5^{\prime}-\mathrm{SH}-\mathrm{T}_{15}$-TTC TCT TCT TCC CTC TTC CCT TC

The working electrodes are initially sonicated in acetone and finally cleaned by immersion in Piranha solution (3:1 conc. $\mathrm{H}_{2} \mathrm{SO}_{4}: \mathrm{H}_{2} \mathrm{O}_{2}$ - Piranha solution is an extremely strong oxidant and should be han- 
dled very carefully), rinsed in deionised water and dried in a stream of nitrogen. The cleaned electrodes are used immediately thereafter for electrochemical characterization.

Self-assembled monolayers (SAMs) of mercaptoundodecanoic acid (MUA) are formed overnight in a $1 \mathrm{mM}$ solution of the alkanethiol prepared in ethanol. The electrodes are subsequently rinsed with ethanol, sonicated for 30 seconds in fresh ethanol and blow dried in a stream of nitrogen. DNA sensors are constructed by depositing approximately $2 \mu \mathrm{l}$ of a mixture of $20 \mu \mathrm{M}$ thiolated DNA probe and $200 \mu \mathrm{M}$ of DT (10-(3,5-bis((6-mercaptohexyl)oxy)phenyl)-3,6,9-trioxadecanol, CAS number 93611552-5, SensoPath Technology Inc., Bozeman, USA), both prepared in $1 \mathrm{M} \mathrm{KH}_{2} \mathrm{PO}_{4}$ and left to immobilize for 3 hours at room temperature in a humidity chamber. The functionalized chips are thoroughly rinsed in PBS Tween, deionized water and dried in a stream of nitrogen. Sensors are stored at $4{ }^{\circ} \mathrm{C}$ for later use. Real surface area measurements are conducted as described by Trasatti et al. [20].

All assay steps are prepared within a polymeric microfluidic system (total volume $30 \mu \mathrm{l}$ ) specifically designed for the electrode array used. The array is initially conditioned with $100 \mu \mathrm{l}$ of PBS Tween followed by an injection of $100 \mu \mathrm{l}$ of $5 \mathrm{nM}$ TACSTD1 target sequence, prepared in PBS Tween $(10 \mathrm{mM}$ phosphate, $138 \mathrm{mM} \mathrm{NaCl}, 0.05 \%$ Tween-20, Ph 7.4).

Hybridisation is allowed to proceed for 60 minutes, followed by the injection of $500 \mu \mathrm{l}$ of PBS Tween to remove any non-specifically bound ssDNA. Finally, the surface bound dsDNA is labeled by injecting $100 \mu \mathrm{l}$ of HRP-labelled complementary secondary probe in PBS Tween, left to hybridise for 30 minutes, and rinsed by injecting $500 \mu \mathrm{l}$ of PBS Tween. PBS Tween is used throughout the assay as high stringency buffer during the hybridization and washing steps as well reduce non-specific interaction between the HRP-label secondary probe and the chip surface. Liquid 3,3', 5, $5^{\prime}$-tetramethyl-benzidine (TMB) ELISA substrate for the horseradish peroxidase (HRP) enzyme label (100 $\mu$ l) is finally injected and the extent of hybridisation measured by pulse amperometry ( $0 \mathrm{~V}$ for $10 \mathrm{~ms}$ followed by $-0.2 \mathrm{~V}$ for $500 \mathrm{~ms})$. The current read at the end of the $-0.2 \mathrm{~V}$ pulse is taken as the hybridisation signal due to the presence of the HRP reporter label. Control sensors consist of electrodes modified with DT only.

\section{Electrochemical characterization}

The resulting electrodes are initially tested electrochemically to estimate their real surface area as well as their capacity to support SAMs of mercaptoundodecanoic acid or thiolated DNA. The electrodes are chemically cleaned and immediately tested in dilute sulphuric acid. The voltammograms recorded for both gold thicknesses (Fig. 4(a)) present the characteristics of polycrystalline gold electrode, i.e. oxidation peaks centred at $1.15 \mathrm{~V}$ and reduction of the formed oxide centred at $0.733 \mathrm{~V}$, showing no contamination of the gold surface by the underlying copper and nickel layers. Based on the quantity of charges required for the reduction of the gold oxide layer the calculated roughness factor for the $3 \mu \mathrm{m}$ thick layers is 7.3 .

The electrode chips are functionalized with SAMs of MUA and TASCTD1 DNA probes coimmobilised in the presence of DT. The cyclic voltammograms recorded in the presence of $5 \mathrm{mM}$ of the redox probe $\mathrm{K}_{3} \mathrm{Fe}\left(\mathrm{CN}_{6}\right)$ in $0.1 \mathrm{M} \mathrm{KCl}$ demonstrate the successful immobilization of both alkanethiol systems as seen by the partial insulation of the electrode to the diffusion of the electroactive probe (Fig. 4(b)). As seen from the voltammogram of the unmodified gold electrode, $\mathrm{K}_{3} \mathrm{Fe}\left(\mathrm{CN}_{6}\right)$ can readily diffuse to the electrode surface resulting in well-defined oxidation and reduction peaks, centred at $0.174 \mathrm{~V}$ and $-0.025 \mathrm{~V}$ respectively. Following the surface modification of the electrodes with either mercaptoundodecanoic acid (MUA) or thiolated DNA, the oxidation/reduction peaks are suppressed. The passivation of the electrode surface hint to the efficient immobilization of a monolayer of 

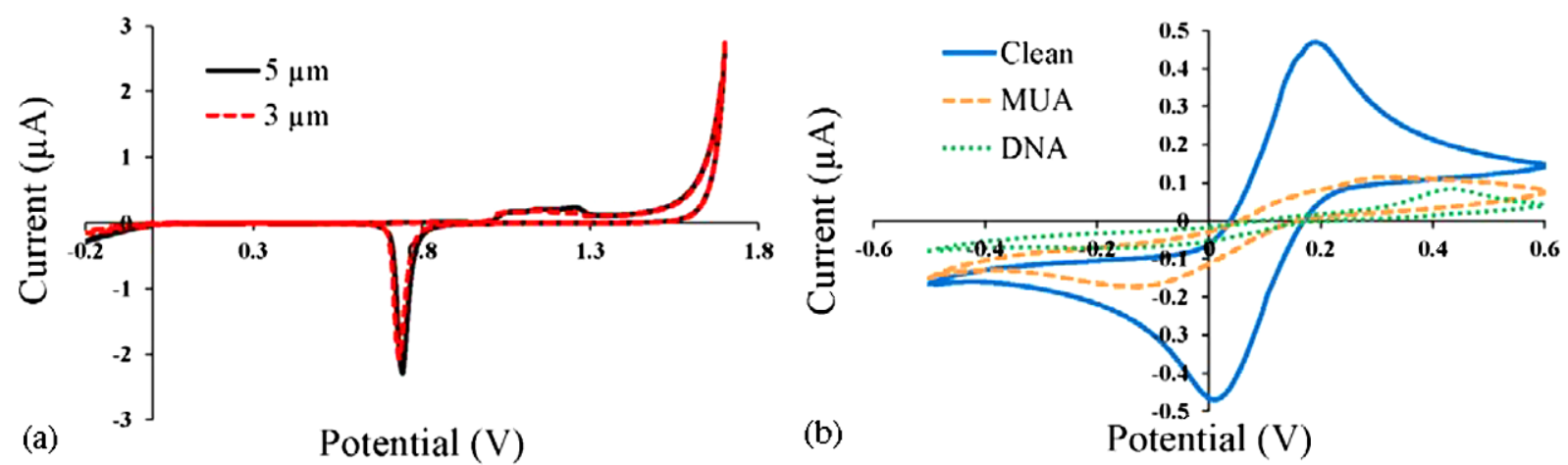

Fig. 4. (a) Cyclic voltammogram recorded in $0.5 \mathrm{M} \mathrm{H}_{2} \mathrm{SO}_{4} 100 \mathrm{mV} \mathrm{s}^{-1}$. (b) Cyclic voltammogram in $5 \mathrm{mM} \mathrm{K}_{3} \mathrm{Fe}\left(\mathrm{CN}_{6}\right)$ prepared in $0.1 \mathrm{M} \mathrm{KCl}$ for clean, mercaptoundodecanoic modified (MUA) and DNA modified (DNA) $3 \mu \mathrm{m}$ thick gold electrodes. (Colors are visible in the online version of the article; http://dx.doi.org/10.3233/BME-140982.)

MUA or DNA, as the redox probe $\mathrm{K}_{3} \mathrm{Fe}\left(\mathrm{CN}_{6}\right)$ can no longer diffuse to the electrode surface and be oxidized/reduced.

Finally, an array is modified with six DNA markers relevant to breast cancer, and tested against $5 \mathrm{nM}$ of the complementary target TACSTD1 in order to determine the functionality of the platform. The assay relies on (i) the formation of a DNA duplex at the electrode surface between the immobilized probe and the complementary target sequence present in solution, followed by (ii) the labelling of the resulting DNA surface-duplex with a secondary DNA probe modified with HRP. Upon injection of the substrate, the enzyme is first oxidized by hydrogen peroxide which further oxidizes the electroactive TMB. By holding the electrode at a reducing potential of $-0.2 \mathrm{~V}$, an enzymatic redox cycling occurs, where the reduced TMB can be further reused by HRP and the resulting current reaches a steady state. The amperometric signal was taken after $500 \mathrm{~ms}$.

Results presented in Fig. 5 show excellent discrimination between the complementary and noncomplementary probes with very low non-specific interactions. The current responses approximate $10 \mathrm{nA}$ for any of the non-specific surfaces, either consisting of DT alone or DT co-assembled with unrelated DNA probes. On the contrary, a signal of $-165.1 \pm 16.9,-92.4 \pm 16.6,-69.3 \pm 5.7$ and $-36.3 \pm 1.9 \mathrm{nA}$ is recorded for the specific sensor modified with the TACSTD1 probe and exposed to sample of varying concentration $(5,2,0.8$ and $0.32 \mathrm{nM}$, respectively) demonstrating the suitability of the electrolytically deposited gold as a possible platform for development of quantitative electrochemical DNA sensors. Moreover, the developed sensor exhibited a theoretical limit of detection of $0.05 \mathrm{nM}$ taken as the concentration value corresponding to the averaged current response for the DT sensors over the entire concentration range plus three times the averaged standard deviation (Fig. 6).

\section{Conclusions}

We have presented a technique to fabricate and functionalise low-density DNA microarrays capable of detecting breast cancer markers. Electroless plating is usually reported in literature for fabricating gold electrodes on PCB [21,22]. However, in electroless plating, gold can be susceptible to contamination of nickel ions [23] and lead to a reduced biocompatibility of the sensing surface [22]. Therefore, in this paper, DNA biosensors have been fabricated by an electrolytic plating procedure, which has allowed depositing a high quality gold layer on copper PCB substrates. Cross-section analysis has shown 


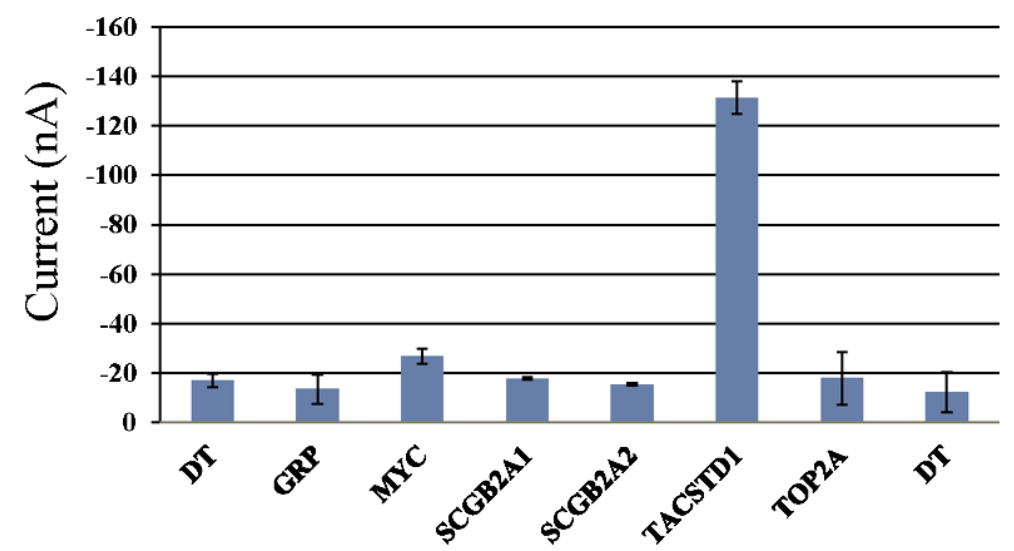

Fig. 5. Electrochemical response measured for $5 \mathrm{nM}$ of TACSTD1 target at the electrodes modified with either complementary TACSTD1 probe, or non-complementary GRP, MYC, SCGB2A1, SCGB2A2, TOP2A or modified solely with the alkanethiol DT (standard deviation calculated for $n=4$ electrodes). (Colors are visible in the online version of the article; http://dx.doi.org/10.3233/BME-140982.)

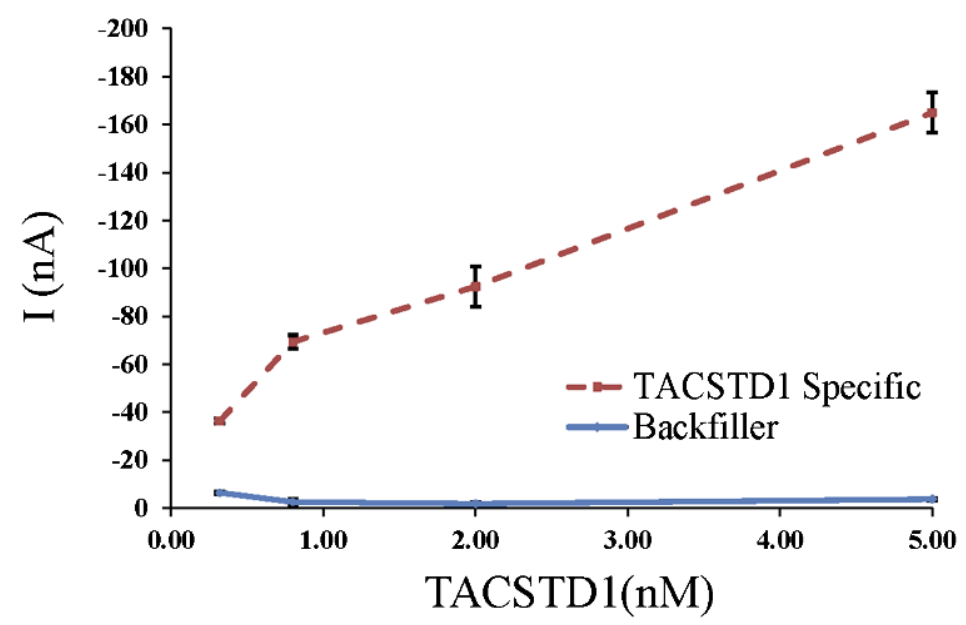

Fig. 6. Response from TACSTD1 specific and DT (Backfiller) sensors for 0.32, 0.8, 2 and $5 \mathrm{nM}$ of TACSTD1 amplicon (standard deviation calculated for $n=3$ electrodes). (Colors are visible in the online version of the article; http://dx.doi.org/10.3233/ BME-140982.)

a negligible variation in the thickness of gold layer. The quality and biocompatibility of the electrodes have been confirmed by electrochemical tests. Voltammograms have proven that the diffusion of metal contaminants, i.e. copper or nickel ions, from the bottom to the top surface of the sensor is prevented. This method can be used for small-scale fabrication in research lab or transferred to industrial mass production to reduce the price per unit of low-density DNA sensors.

Gold electrodes have been functionalised with SAMs of MUA and TASCTD1 DNA probes in presence of DT and tested for the identification of breast cancer markers. Experiments have shown that the functionalization is effective in reducing non-specific interactions and improving the detection limit of the biosensor. In fact, our method allows discriminating non-specific bindings with GRP, MYC, SCGB2A1, SCGB2A2, TOP2A and DT from the target TACSTD1, with a difference of $100 \mathrm{nA}$, approximately. Finally, the limit of detection of $0.05 \mathrm{nM}$ represents a threefold improvement over previous similar work 
[19]. This low-density DNA sensor has the potential to be implemented in low cost miniaturized labon-a-chip systems capable of complex and real time measurements for point-of-care applications and pharmacological personalised therapies.

\section{Acknowledgements}

This work has been carried out with financial support from the European Commission Seventh Framework program under grant agreements FP7-IEF-221198 (Marie Curie Action) and FP7-ICT-257743 (MIRACLE - http://www.miracle-fp7.eu/).

\section{References}

[1] D.R. Reyes, D. Iossifidis, P.A. Auroux and A. Manz, Micro total analysis systems. 1. Introduction, theory, and technology, Anal. Chem. 74 (2002), 2623-2636.

[2] G. Marchand, P. Broyer, V. Lanet, C. Delattre, F. Foucault, L. Menou, B. Calvas, D. Roller, F. Ginot, R. Campagnolo and F. Mallard, Opto-electronic DNA chip-based integrated card for clinical diagnostics, Biomed. Microdevices 10 (2008), 35-45.

[3] A. McShea, M.W. Marlatt, H.G. Lee, S.M. Tarkowsky, M. Smit and M.A. Smith, The application of microarray technology to neuropathology: cutting edge tool with clinical diagnostics potential or too much information?, J. Neuropathol. Exp. Neurol. 65(11) (2006), 1031-1039.

[4] G.M. Swain, Solid electrode materials: Pretreatment and activation, in: Handbook of Electrochemistry, C.G. Zoski, ed., 1st edn, Elsevier, New York, 2007, pp. 111-150.

[5] W. Yang, O. Auciello, J.E. Butler, W. Cai, J.A. Carlisle, J.E. Gerbi et al., DNA-modified nanocrystalline diamond thinfilms as stable, biologically active substrates, Nature Mater. 1 (2002), 253-257.

[6] J. Xu, J.J. Zhu, Q. Huang and H.Y. Chen, A novel DNA-modified indium tin oxide electrode, Electrochem. Commun. 3(11) (2001), 665-669.

[7] R. Shukla, V. Bansal, M. Chaudhary, A. Basu, R.R. Bhonde and M. Sastry, Biocompatibility of gold nanoparticles and their endocytotic fate inside the cellular compartment: A microscopic overview, Langmuir 21(23) (2005), 10644-10654.

[8] K. Xu, J. Huang, Z. Ye, Y. Ying and Y. Li, Recent development of nano-materials used in DNA biosensors, Sensors 9(7) (2009), 5534-5557.

[9] R. Popovtzer, T. Neufeld, E.Z. Ronb, J. Rishpon and Y. Shacham-Diamand, Electrochemical detection of biological reactions using a novel nano-bio-chip array, Sensor Actuat. B 119(2) (2006), 664-672.

[10] I. Kleps, M. Danila, A. Angelescu, M. Miu, M. Simion, T. Ignat et al., Gold and silver/Si nanocomposite layers, Mat. Sci. Eng. C-Bio. S. 27 (2007), 1439-1443.

[11] D. Xu, K. Huang, Z. Liu, Z. Liu and L. Ma, Microfabricated disposable DNA sensors based on enzymatic amplification electrochemical detection, Electroanal. 13(10) (2001), 882-887.

[12] Z. Xiaoa, M. Xua, T. Ohgib, N. Ishikawaa and D. Fujitaa, Controlled deposition of single DNA molecules on bare gold electrodes, Physica E 21 (2004), 1098-1101.

[13] N. Bassil, E. Maillart, M. Canva, Y. Lévya, M.C. Millot, S. Pissard et al., One hundred spots parallel monitoring of DNA interactions by SPR imaging of polymer-functionalized surfaces applied to the detection of cystic fibrosis mutations, Sensor Actuat. B 94(3) (2003), 313-323.

[14] A. Manickam, A. Chevalier, M. McDermott, A.D. Ellington and A. Hassibi, A CMOS electrochemical impedance spectroscopy (EIS) biosensor array, IEEE Trans. Biomed. Circuits Syst. 4(6) (2010), 379-390.

[15] J.W. Ko, H.C. Koo, D.W. Kim, S.M. Seo, T.J. Kang, Y. Kwon et al., Electroless gold plating on aluminum patterned chips for CMOS-based sensor applications, J. Electrochem. Soc. 157(1) (2010), D46-D49.

[16] D.S. Lee, S.H. Park, K.H. Chung and H.B. Pyo, A disposable plastic-silicon micro PCR chip using flexible printed circuit board protocols and its application to genomic DNA amplification, IEEE Sensors Journal 8(5) (2008), 558-564.

[17] A. Wego, S. Richter and L. Pagel, Fluidic microsystems based on printed circuit board technology, J. Micromech. Microeng. 11(5) (2001), 528-531.

[18] T. Merkel, M. Graeber and L. Pagel, A new technology for fluidic microsystems based on PCB technology, Sensor Actuat. A 77(2) (1999), 98-105.

[19] O.Y.F. Henry, J.L. Acero Sanchez and C.K. O'Sullivan, Bipodal PEGylated alkanethiol for the enhanced electrochemical detection of genetic markers involved in breast cancer, Biosens. Bioelectron. 26 (2010), 1500-1506. 
[20] S. Trasatti and O.A. Petrii, Real surface-area measurements in electrochemistry, Pure Appl. Chem. 63(5) (1991), 711-734.

[21] J.-G. Lee, K. Yun, G.-S. Lim, S.E. Lee, S. Kim and J.-K. Park, DNA biosensor based on the electrochemiluminescence of $\mathrm{Ru}(\mathrm{bpy})_{3}^{2+}$ with DNA-binding intercalators, Bioelectrochemistry 70(2) (2007), 228-234.

[22] F. Destro, M. Borgatti, B. Iafelice, R. Gavioli, T. Braun, J. Bauer, L. Böttcher, E. Jung, M. Bocchi, R. Guerrieri and R. Gambari, Effects of biomaterials for Lab-on-a-chip production on cell growth and expression of differentiated functions of leukemic cell lines, J. Mater. Sci. Mater. Med. 21 (2010), 2653-2664.

[23] Y. Okinaka, Electroless plating of gold and gold alloys, in: Electroless Plating - Fundamentals and Applications, G.O. Mallory and J.B. Hajdu, eds, Cambridge Univ. Press, 1990. 